\title{
Review Article \\ Early versus Delayed Oral Feeding in Patients following Total Laryngectomy
}

\author{
Ashley Hay, ${ }^{1,2}$ Lisa Pitkin, ${ }^{1}$ and Kurinchi Gurusamy ${ }^{3}$ \\ ${ }^{1}$ ENT Department, Royal Surrey County Hospital, Guildford, Surrey GU2 7XX, UK \\ ${ }^{2}$ ENT Department, St George's Hospital, Blackshaw Road, Tooting, London SW17 0QT, UK \\ ${ }^{3}$ Department of Surgery, Royal Free Campus, University College London, London NW3 2QG, UK
}

Correspondence should be addressed to Ashley Hay; ashley.hay@doctors.net.uk

Received 21 July 2014; Accepted 29 August 2014; Published 28 September 2014

Academic Editor: Giuseppe Mercante

Copyright (C) 2014 Ashley Hay et al. This is an open access article distributed under the Creative Commons Attribution License, which permits unrestricted use, distribution, and reproduction in any medium, provided the original work is properly cited.

Objectives. To assess the effects of early oral feeding in laryngectomy patients versus delayed oral feeding. The outcomes used are mortality, pharyngocutaneous fistula rate, quality of life, hospital length of stay, and complications. Method. We performed searches within five major databases until June 2013. We considered randomised control trials (RCTs) and included nonrandomised studies for the assessment of harms. Results. We included four RCTs for assessment of benefits and three nonrandomised studies for assessment of harms (393 participants). There was no statistically significant difference detected in mortality at six months, pharyngocutaneous fistulae, or complications. The length of hospital stay was shorter in the early feeding group, MD -2.72 days [95\% CI -5.34 to -0.09]. Conclusion. Early oral feeding appears to have similar incidence of complications and has the potential to shorten the length of hospital stay. Further well-designed RCTs are necessary because of weakness in the available evidence.

\section{Introduction}

Total laryngectomy is widely performed across the world [1]. Despite changes in treatment protocols over the last twenty years following the radiation therapy oncology group (RTOG) [2] and Veterans Affairs [3] studies towards organ preserving protocols in laryngeal carcinoma, total laryngectomy continues to be an important treatment option.

Heath episode statistics (HES) data from England in 2011-2012 suggests that up to 600 laryngectomies are being performed per year in the UK [4] and 3414 per year in USA [5].

Squamous cell carcinoma of the larynx or hypopharynx is the underlying pathology in over $95 \%$ of people undergoing total laryngectomies [6], with the other main indication being life threatening laryngeal dysfunction with aspiration seen in certain neurological conditions [7]. The aims of total laryngectomy are to provide a safe airway after the removal of larynx and establish enteral continuity allowing for oral feeding.
The main choice is starting oral feeding between at an early stage and at a delayed or late stage. Typically most patients wait a minimum of 7 days following total laryngectomy before oral feeding is started. $84 \%$ of 141 American surgeons reported [8] that they waited until after the seventh postoperative day in a questionnaire survey by Boyce and Meyers in 1989. However periods of up to three weeks were reported. The choice often depends on the surgeon's experience and preference and on the patient's comorbidities and the tumor characteristics [9].

The reason for late feeding has been argued that sufficient time is needed for the pharyngeal suture line to heal $[10,11]$. It has been postulated that the wound's weakest point was at seven to ten days after surgery and that the collagen phase of wound healing occurs between the 5th and 14th days. Early studies in the 1970s identified that early feeding following total laryngectomy may be a risk factor for pharyngocutaneous fistula $[12,13]$. However, risk factors for the development of a fistula are several and often overlapping [11]. It has been seen that the development of a fistula often 
occurs before oral feeding in groups of patients that are receiving a delayed oral feeding regime [14] suggesting that the early feeding may not be responsible for the development of fistula. Early oral feeding offers the advantages of early enteral nutrition that may lead to shortening hospital stay and possible swallowing function improvements. There might be a reduction in septic complications, reduction in nasogastric feeding [14], and earlier return to normal activities.

There are currently no guidelines regarding the timing of commencement of oral feeding in patients undergoing total laryngectomy and this study aims to find the available evidence for the benefits and harms of early versus delayed oral feeding following laryngectomy.

\section{Methods}

2.1. Identification of Trials and Data Extraction. Randomised control trials (RCTs) were considered irrespective of the use of blinding, language status and date of publication, setting, or sample sizes that compared early oral feeding in laryngectomy patients (before seven days) with delayed or late oral feeding (seven days or later) for benefits and nonrandomised studies that compared early with delayed oral feeding for assessment of harms [15].

The primary outcomes for this study were mortality at six months, proportion of patients developing a pharyngocutaneous fistula, and quality of life with a validated quality of life tool. Secondary outcomes were complications (Clavien-Dindo classification [16]) and length of stay from the operation date to the day of discharge from hospital.

The following databases were searched in June 2013: Medline PubMed, Embase, Cochrane Central, Science Citation Index, and WHO Trials Registration. The search strategies can be found in Supplementary Tables 1 and 2 in Supplementary Material available online at http://dx.doi.org/10.1155/2014/ 420239.

Between two authors (Ashley Hay and Lisa Pitkin), all identified references were screened independently to identify references that potentially met the inclusion criteria. Full texts were obtained when at least one of the authors selected the reference for further evaluation. Final decisions on the inclusion or exclusion were made on reading the full text. No language or publication restrictions were applied.

2.2. Assessment of Risk of Bias. The instructions given in the Cochrane Handbook for Systematic Reviews of Interventions [15] were followed in the assessment of risk of bias in the included studies. According to empirical evidence [17-20] risk of bias in the included trials was based on the following risk of bias domains: sequence generation, allocation concealment, blinding of participants, incomplete outcome data, and selective outcome reporting. The risk of bias was classified as low, unclear, or high risk of bias for each domain and trials that were at low risk of bias in all the domains were considered to be trials at "low risk of bias."

2.3. Statistical Analysis. The statistical software package RevMan 5.2 [21] provided by the Cochrane collaboration for analysis was used. For binary outcomes (pharyngocutaneous fistula and complications), the risk ratio (RR) with 95\% confidence interval (CI) was calculated. For continuous outcomes, the mean difference (MD) with 95\% CI was calculated, such as hospital stay where the results from all the studies could be converted to the same units, and for outcomes such as quality of life where different studies could report different scales the standardised mean difference outcome was planned. To combine the hazard ratios for time-to-event outcomes such as survival the generic inverse variance method was planned, but there was not adequate data available in the studies. For the analysis of count data outcomes such as combined complication events from different grades of complication, the rate ratio was calculated and combined using generic variance method. Both the Mantel-Haenszel $(\mathrm{MH})$ randomeffects model [22] and fixed-effect model for meta-analyses [23] were used. With outcomes in which the event occurred less than $1 \%$ (mortality at 6 months), the Peto odds ratio (OR) was used.

An intention-to-treat (ITT) analysis was performed for all outcome calculations [24]. For continuous outcomes, available case analysis was used. The standard deviation from $P$ values was imputed and the median for the meta-analysis when the mean was not available was used.

Heterogeneity was explored using the $\chi^{2}$ test with significance set at $P$ value 0.10 and measured the quantity of heterogeneity by the $I^{2}$ statistic [15].

To explore reporting bias visual asymmetry of the funnel plot $[25,26]$ and linear regression to determine funnel plot asymmetry [25] in the presence of at least ten trials was planned, but there were not a sufficient number of trials available.

Subgroup analysis for the following factors was planned of primary tracheoesophageal punctures versus none and single layer pharyngeal closure versus more than one layer closure on incidence of pharyngocutaneous fistula formation. Subgroup analysis to assess the effect of early versus delayed oral feeding on each grade of complication was also planned. A $P$ value of less than 0.05 for $\chi^{2}$ test to identify the differences between subgroups was planned.

\section{Results}

3.1. Search Results. A total of 84 references were identified by the search strategy for RCTs (see Supplementary Table 1). Following the removal of irrelevant and duplications one study was excluded for not being a randomized control trial and one trial was excluded because the intervention was different to the definition used for this review. Four studies were considered for analysis with a total of 224 participants [27-30] (see Figure 1).

Electronic searches of Medline PubMed and Embase were performed with a strategy that did not filter on the basis of trial design to identify studies for inclusion in calculation of harm (see Supplementary Table 2). The results were then reviewed to identify studies that included a control group and intervention group. A total of 250 studies were identified and following removal of irrelevant and duplicate studies 
Identification of studies flow diagram

RCT search

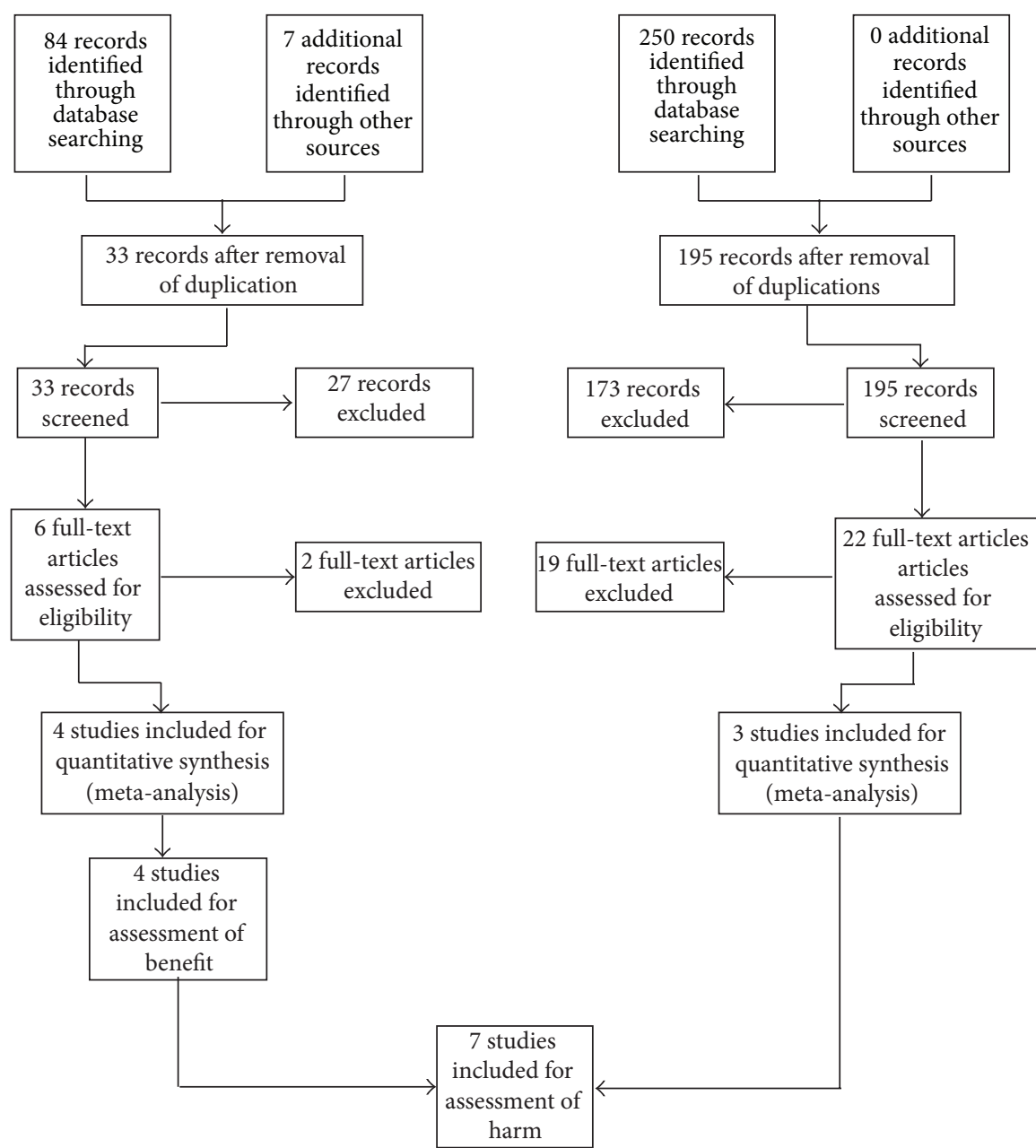

Figure 1: Reference flow diagram of studies included for randomised controlled trials, nonrandomised controlled trials, and analysis of benefit and harm.

three nonrandomised studies [14, 31, 32] were identified for inclusion (see Figure 1). An additional 169 participants were identified from these three nonrandomised studies resulting in a total of 393 participants for the assessment of harm (mortality and pharyngocutaneous fistula).

\subsection{Description of Included Trials}

3.2.1. Randomised Control Trials. All four studies [27-30] randomised their patients following surgery. The number of participants in each trial ranged from 28 to 67 . Whilst surgical technique for total laryngectomy within studies was quoted as being standardised, variation between studies did exist. Pharyngeal closure varied from single layer [28] to two layers [27, 30] or was not mentioned [29]. Tracheoesophageal puncture and tubes were performed in all participants in some studies $[27,30]$ and in none of the participants [28] in another and not mentioned in the fourth [29]. There was also variation within the inclusion criteria and exclusion criteria for participants within the different studies. Some included participants that required pharyngeal resection [28-30] whilst others excluded these patients [27]. Some included patients that had previous surgery or radiotherapy $[27,30]$ whilst others excluded these $[28,29]$. The use or description of nasogastric tube [28-30] or primary tracheoesophageal feeding tubes [27] also varied between studies.

The quality of outcome reporting varied from detailed patient level data [30] to minimal outcome results for complications [28]. The reporting of complications, management of fistulas, and return to theatre were also poorly documented in the studies. None of the studies reported long-term mortality, recurrence, or quality of life outcomes. The majority of patients included in this study underwent primary surgery. A summary can be seen in Table 1. 
TABLE 1: Summary of included studies.

\begin{tabular}{|c|c|c|c|c|c|}
\hline Study details & $\begin{array}{c}\text { Number of } \\
\text { patients }\end{array}$ & $\begin{array}{l}\text { Early feeding } \\
\text { (intervention) }\end{array}$ & Late feeding (control) & Inclusion & Exclusion \\
\hline $\begin{array}{l}\text { Seven et al. [27] } 2003 \\
\text { Turkey } \\
\text { RCT }\end{array}$ & 65 & $\begin{array}{l}\text { Liquid diet } 24 \text { hours } \\
\text { following surgery and } \\
\text { oral diet as tolerated } \\
\text { ( } 32 \text { patients) }\end{array}$ & $\begin{array}{l}\text { Fed through TEP tube } \\
\text { and started oral feeds } \\
\text { on the } 7 \text { th } \\
\text { postoperative day } \\
\text { (33 patients) }\end{array}$ & $\begin{array}{l}\text { Total laryngectomy } \\
\text { surgery with primary } \\
\text { closure for malignant } \\
\text { cancers of larynx who } \\
\text { were also candidates for } \\
\text { primary TEP November } \\
1999 \text { to March } 2002\end{array}$ & $\begin{array}{l}\text { Requirement for tissue } \\
\text { flap TEP not performed }\end{array}$ \\
\hline $\begin{array}{l}\text { Sharifian et al. [28] } \\
2008 \\
\text { Iran } \\
\text { RCT }\end{array}$ & 25 & $\begin{array}{l}\text { Sips of water started } \\
\text { on the } 3 \text { rd } \\
\text { postoperative day and } \\
\text { built up ( } 13 \text { patients) }\end{array}$ & $\begin{array}{l}\text { Oral feeds started on } \\
\text { the } 7 \text { th day if fistula is } \\
\text { not present ( } 12 \\
\text { patients) }\end{array}$ & $\begin{array}{l}\text { Total laryngectomy for } \\
\text { malignant tumours of } \\
\text { larynx, September } \\
\text { 2002-October } 2006\end{array}$ & $\begin{array}{l}\text { Previous surgery for } \\
\text { tumour } \\
\text { Surgery for aspiration } \\
\text { Invasive thyroid cancers } \\
\text { Postcricoid/oesophagus } \\
\text { cancers } \\
\text { Preoperative } \\
\text { radiotherapy and partial } \\
\text { laryngectomy surgeries }\end{array}$ \\
\hline $\begin{array}{l}\text { Song et al. [29] } 2003 \\
\text { China } \\
\text { RCT }\end{array}$ & 42 & $\begin{array}{l}\text { Oral feeding } 48-72 \\
\text { hours after surgery ( } 21 \\
\text { patients) }\end{array}$ & $\begin{array}{l}\text { Oral feeding } 10-12 \\
\text { days after surgery } \\
\text { (21 patients) }\end{array}$ & $\begin{array}{l}\text { Total laryngectomy for } \\
\text { larynx and pyriform } \\
\text { fossa tumours of } \\
\text { squamous cell } \\
\text { carcinomas July } \\
\text { 2000-July } 2002 \\
\end{array}$ & Not clear \\
\hline $\begin{array}{l}\text { Volling et al. [30] } \\
2001 \\
\text { Germany } \\
\text { RCT }\end{array}$ & 42 & $\begin{array}{l}\text { Staggered feeding } \\
\text { regime. } \\
\text { All patients orally fed } \\
\text { before the 7th day } \\
\text { were included ( } 31 \\
\text { patients) }\end{array}$ & $\begin{array}{l}\text { Staggered feeding } \\
\text { regime with all } \\
\text { patients fed on the } 7 \text { th } \\
\text { day or afterwards } \\
\text { included (11 patients) }\end{array}$ & $\begin{array}{l}\text { Total laryngectomy for } \\
\text { advanced or recurrent } \\
\text { cancer February 1, 1996, } \\
\text { to June } 30,1996\end{array}$ & $\begin{array}{l}\text { Distant metastasis } \\
\text { Need for tissue flap }\end{array}$ \\
\hline $\begin{array}{l}\text { Aswani et al. [31] } \\
2009 \\
\text { South } \\
\text { Africa } \\
\text { CCT }\end{array}$ & 79 & $\begin{array}{l}\text { Clear oral fluids from } \\
\text { postoperative day } 2 \text {, } \\
\text { to be built up to free } \\
\text { fluids on the } 3 \text { rd day, } \\
\text { soft diet on the } 4 \text { th } \\
\text { day, and normal diet } \\
\text { on the } 5 \text { th day ( } 40 \\
\text { patients) }\end{array}$ & $\begin{array}{l}\text { Tube fed (either } \\
\text { nasogastric or TEP) } \\
\text { until the } 7 \text { th day } \\
\text { when oral feeding was } \\
\text { started ( } 39 \text { patients) }\end{array}$ & $\begin{array}{l}\text { Total laryngectomy } \\
\text { November } 2002 \text { to } \\
\text { December } 2006\end{array}$ & $\begin{array}{l}\text { Myocutaneous flaps } \\
\text { Tumour extension into } \\
\text { tongue base } \\
\text { Operative complication } \\
\text { (cricopharyngeal } \\
\text { myotomy breaching } \\
\text { mucosa) }\end{array}$ \\
\hline
\end{tabular}

Medina and Khafif

[32] 2001

USA

CCT
Oral feeding at 48

hours

(group one 20

patients and group

two 35 patients)
Feeding started on 7 to 10 days following surgery (18 patients)
Total laryngectomy for cancer of larynx Normal preoperative blood tests
Neck irradiation (any preoperative irradiation apart from that for $\mathrm{T} 1 / 2$ laryngeal cancers with narrow field irradiation) Previous cancer operation in aerodigestive tract Patients with synchronous tumours

Postcricoid tumours Myocutaneous flap Primary TEP Poor preoperative nutrition Salvage surgery Liver disease, chronic obstructive airways disease, or diabetes Systemic complication in postoperative period 


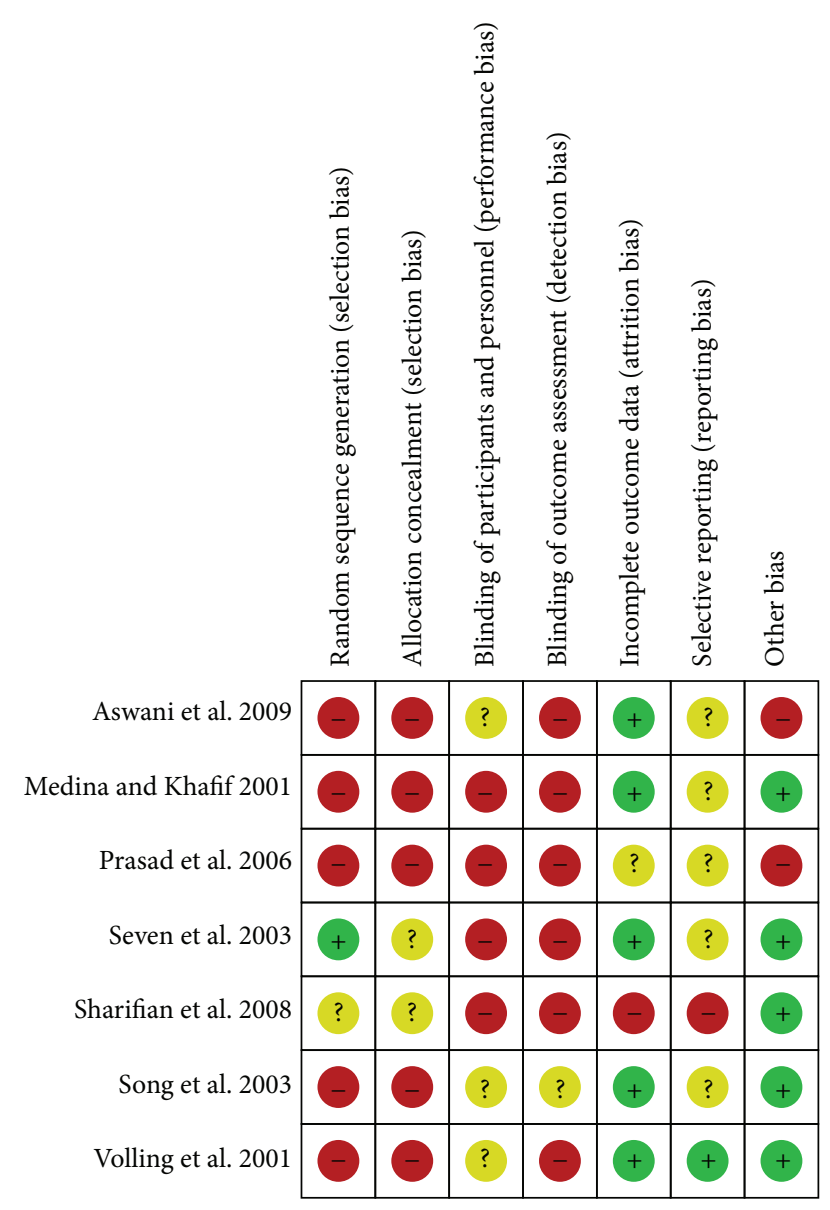

FIGURE 2: Risk of bias summary. Red circle indicates high risk of bias, yellow circle indicates risk unable to be assessed, and green circle indicates low risk of bias.

3.2.2. Nonrandomised Studies. This group included two prospective cohort studies [14, 32] and a study that used a historical control group [31]. Inclusion and exclusion criteria in the early and delayed feeding groups varied raising concerns of selection bias (see Table 1).

3.3. Risk of Bias. The design of surgical trials is made difficult by the inability to blind patients and care givers. The surgeon is very likely to be involved in postoperative care. This puts all studies at high risk of performance bias and detection bias because awareness of which study arm a patient is allocated to will be known to the treating team and study authors. This could affect the subsequent treatment and the detection of postoperative complications. See Figure 2 for a summary of risk of bias assessments.

\subsection{Effect Estimates}

3.4.1. Primary Outcomes. There were no postrandomization dropouts and an ITT analysis was performed in all cases.

Mortality at 6 Months. All 7 studies reported 6-month mortality rates but there were only two studies that had any events present $[27,30]$. Mortality was less than $1 \%$ in the intervention and control groups so Peto's odds ratio was used. A total of 393 participants are included, but only 2 studies with a total of 99 patients contributed to pooled result (see Figure 3):

\section{OR $0.25 ; 95 \%$ CI 0.02 to 2.76 .}

The confidence intervals were wide and the test for overall effect is not significant. There is no evidence of significant heterogeneity.

Long-Term Survival. Long-term survival was not reported in any of the studies.

The Proportion of Patients Developing Pharyngocutaneous Fistulas. All studies included information on the occurrence of postoperative pharyngocutaneous fistula within the first six months of surgery. A total of 393 participants are included (see Figure 4).

Pooled results including all studies are

RR 0.82; 95\% CI 0.44 to 1.50 .

Their confidence intervals were wide and the test for overall effect is not significant. There is no evidence of significant heterogeneity. All studies (RCTs and non-RCTs) had events and contributed to pooled results.

Quality of Life Measured with a Validated Quality of Life Tool. No quality of life data in any form was presented in any of the studies.

\subsubsection{Secondary Outcomes}

Complications (Clavien-Dindo Classification [16]). Complications data was reported in the four RCTs and whilst reported in the non-RCTs the information on the study group to which the complication applied to was not available. The available data was of varying details and qualities. Fistula rates were reported well. Only one study reported grade 3 complications and there were no grade 4 complications reported. A selected number of complications were reported overall but there was a lack of robust information, with some studies giving fuller accounts of complications $[27,30]$ than others [28, 29]. Fiftyone events or complications were reported across all grades of complications in the four RCTs. The pooled data of all complications is presented here (see Figure 5). Consider the following:

\section{RR $0.91 ; 95 \%$ CI 0.58 to 1.43 .}

Their confidence intervals were wide and the test for overall effect is not significant. There is no evidence of significant heterogeneity between the studies.

Length of Stay from the Operation Date to the Day of Discharge from Hospital. Mean postoperative stay data was presented in three RCTs (149 participants) (see Figure 6):

(i) $\mathrm{MD}-2.72$ days; $95 \% \mathrm{CI}-5.34$ to -0.09 ; 


\begin{tabular}{|c|c|c|c|c|c|c|c|c|c|c|}
\hline \multirow{3}{*}{$\begin{array}{l}\text { Study or subgroup } \\
\text { Aswani et al. } 2009\end{array}$} & \multicolumn{2}{|c|}{ Early oral feeding } & \multicolumn{2}{|c|}{ Delayed oral feeding } & \multirow{2}{*}{ Weight } & \multirow{2}{*}{$\begin{array}{c}\text { Peto odds ratio } \\
\text { Peto, fixed, } 95 \% \text { CI }\end{array}$} & \multirow{2}{*}{\multicolumn{4}{|c|}{$\begin{array}{c}\text { Peto odds ratio } \\
\text { Peto, fixed, } 95 \% \text { CI }\end{array}$}} \\
\hline & \multirow{2}{*}{$\begin{array}{c}\text { Events } \\
0\end{array}$} & \multirow{2}{*}{$\begin{array}{c}\text { Total } \\
40\end{array}$} & \multirow{2}{*}{$\begin{array}{c}\text { Events } \\
0\end{array}$} & \multirow{2}{*}{$\begin{array}{c}\text { Total } \\
39\end{array}$} & & & & & & \\
\hline & & & & & & Not estimable & & & & \\
\hline Medina and Khafif 2001 & 0 & 54 & 0 & 19 & & Not estimable & & & & \\
\hline Prasad et al. 2006 & 0 & 40 & 0 & 38 & & Not estimable & & & & \\
\hline Seven et al. 2003 & 1 & 32 & 1 & 22 & \multirow{2}{*}{$71.0 \%$} & $0.68[0.04,11.67]$ & & & & \\
\hline Sharifian et al. 2008 & 0 & 13 & 0 & 12 & & Not estimable & & & & \\
\hline Song et al. 2003 & 0 & 21 & 0 & 21 & & Not estimable & & & - & \\
\hline Volling et al. 2001 & 0 & 31 & 1 & 11 & $29.0 \%$ & $0.02[0.00,1.90]$ & & & & \\
\hline Total $(95 \% \mathrm{CI})$ & & 231 & & 162 & $100.0 \%$ & $0.25[0.02,2.76]$ & & & & \\
\hline Total events & 1 & & 2 & & & & & & & \\
\hline \multicolumn{7}{|c|}{ Heterogeneity: $\chi^{2}=1.61, \mathrm{df}=1(P=0.20) ; I^{2}=38 \%$} & 0.001 & 0.1 & 10 & 1000 \\
\hline \multicolumn{7}{|c|}{ Test for overall effect: $Z=1.13(P=0.26)$} & Favour & feeding) & Favours ( & feeding) \\
\hline
\end{tabular}

FIGURE 3: Forest plot of comparison: comparison of early oral feeding with delayed oral feeding Peto odds ratio, mortality at 6 months.

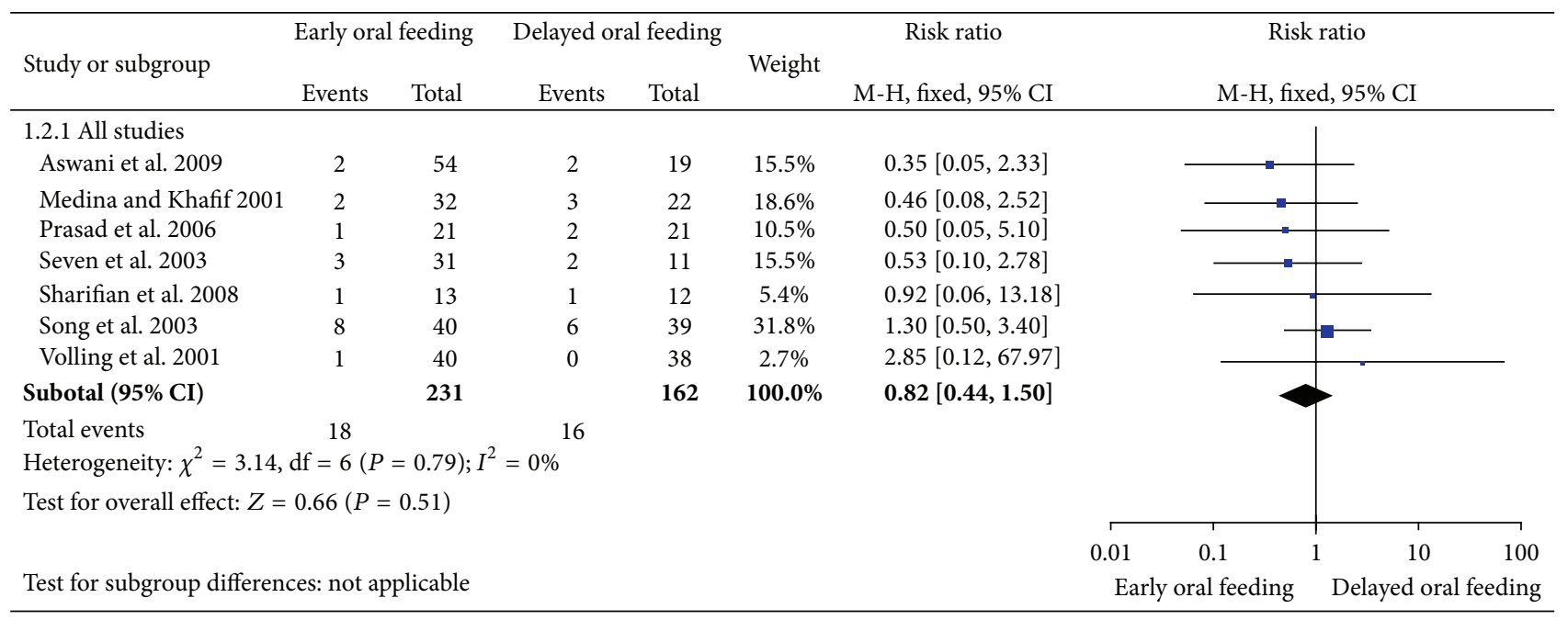

FIGURE 4: Forest plot of comparison: comparison of early oral feeding with delayed oral feeding MH fixed-effects models, pharyngocutaneous fistula rate.

(ii) test for overall effect: $Z=2.03(P=0.04)$ showing statistical evidence of a difference between the two groups.

A summary of findings table summarizes these results with illustrative comparative risks (see Table 2).

\subsubsection{Sensitivity Analysis}

Sensitivity Analysis for Pharyngocutaneous Fistula Outcome. To exclude studies at higher risk of bias due to study design, we performed subgroup analysis including only RCTs. The results did not alter significantly by excluding the nonrandomised studies.

3.4.4. Subgroup Analysis. There was only one study [28] in the one layer closure group so this analysis was not performed. Analysis of complications in the different grades as subgroups was not performed because there were no reported events in grades 1 and 4 complication groups and there were too few events in each subgroup. Comparing studies that performed a tracheoesophageal puncture [27, 30, 31] with nasogastric tubes $[14,28,32]$ did not alter the results.

3.4.5. Funnel Plot. A funnel plot and linear regression analysis was planned but because of an insufficient number of included trials (a minimum of 10 is required) this was not performed.

\section{Discussion}

Starting oral feeding is a significant milestone for the rehabilitation of a patient following total laryngectomy. It can be seen as success for the patient and surgeon, allowing the patient to return to a normal diet.

The proportion of deaths in the intervention group was $0.4 \%$ (1 out of 231 participants) compared to the control group proportion that was $1.2 \%$ ( 2 out of 162 participants). The Peto odds ratio (OR) point estimate was 0.26 ; however the confidence intervals $(\mathrm{CI})$ were wide including 1 indicating chance of no difference. There were also very few deaths 


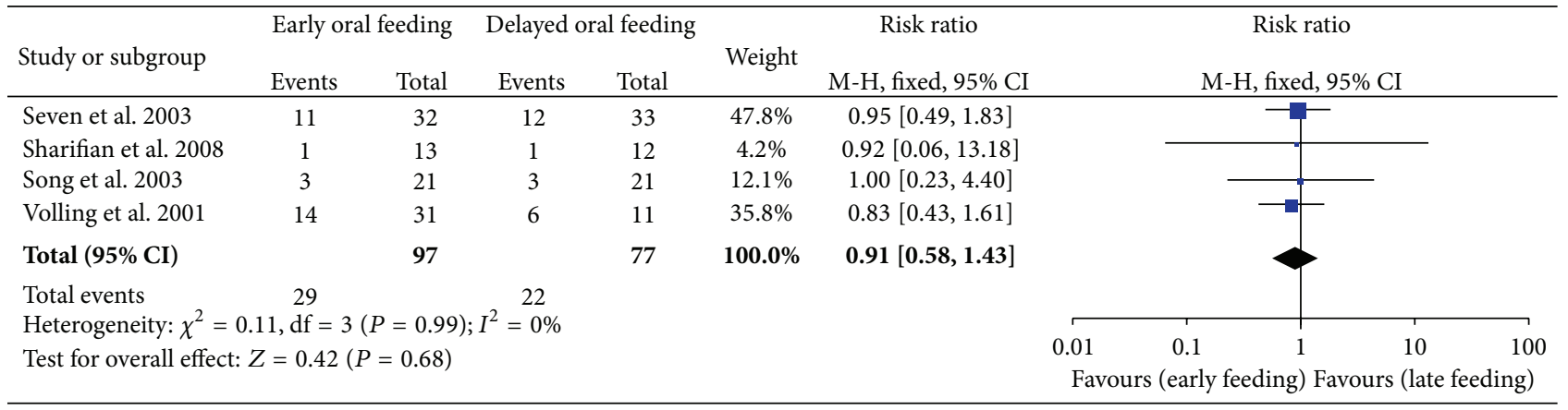

Figure 5: Forest plot of comparison: comparison of early oral feeding with delayed oral feeding MH fixed-effects models, pooled complications.

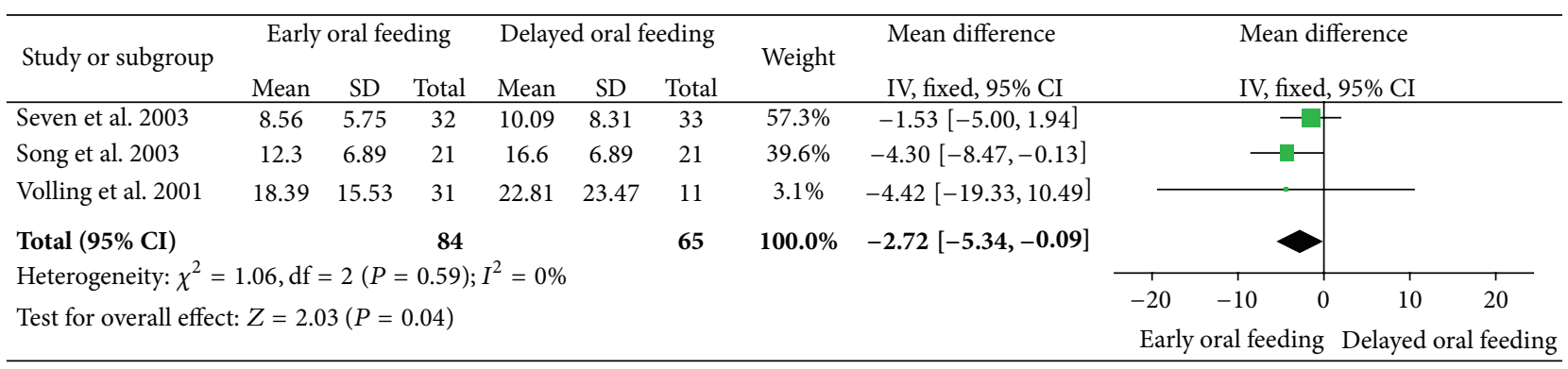

FIGURE 6: Forest plot of comparison: comparison of early oral feeding with delayed oral feeding MH fixed-effects models, length of postoperative stay in days.

making judgments uncertain for this population. Only two trials had any events. The quality of evidence used to make these estimates was generally poor. However these pooled results did not show an increase in mortality with early oral feeding.

Pharyngocutaneous fistula is one of the most common complications following total laryngectomy. All studies reported this complication up to 6 months following surgery. This is reasonable because late fistulas are rare and usually due to some other types of treatment modality. The quality of the evidence to detect a difference suffered from weak design and high risk of selection bias. A total number of 18 fistulas occurred in the intervention group of 231 participants (7.79\% fistula rate) and 16 fistulas occurred in the control group of 162 participants (9.88\% fistula rate). Pooled results for harmful effect estimates were again used (RR of 0.82). There are wide CIs ( 0.44 to 1.50$)$. There is no evidence that either intervention or treatment group is associated with more fistulas.

The first consideration for early oral feeding after total laryngectomy was by Alonso Justo in 1954 [33] in which nasogastric feeding tubes were not used postoperatively. A fistula rate of $9 \%$ was reported by Aprigliano in which he also did not use a nasogastric tube in his case series of 625 total laryngectomies [34] and did not feed his patients on the third postoperative day. This compares favorably fistula rates in delayed postoperative oral feedings groups with fistula rates reported to vary between $2 \%$ and 35\% [35]. In Boyce and
Meyers's cases series they showed that early oral feeding did not have a greater incidence of fistula [8]. Medina and Khafif compared a control group with an early feeding group and reported a fistula rate of $11 \%$ in their control group and 3.6\% in early feeding group [32]. Akyol et al. reported a study of 110 patients fed on day one or two with a fistula rate of $21 \%$ [36].

The reporting of complications in the RCTs was variable and was not robust. The rate ratio point estimate and CI were $0.66[0.37,1.21]$ for all (pooled) complications. A clinically significant increase or decrease in the complications cannot be ruled out.

The early feeding group went home on average nearly 3 days earlier than the control group. Some studies excluded patients with certain comorbidities or those requiring more extensive surgery. However in patients who do not have extensive comorbidities or require procedures in addition to total laryngectomy, a reduced length of stay of 3 days is a meaningful result that could be associated with reduced hospital occupancy and costs. Unfortunately none of the studies reported if any repeat admissions occurred following discharge and this would need to be known before any interpretation of this outcome can be done accurately.

In other surgical specialties such as colorectal surgery enhanced recovery and early oral feeding have been shown to be safe and convey positive postoperative benefits [3739]. Similar to head and neck surgery, postoperative management of abdominal surgery has traditionally relied on nasogastric tubes and avoidance of oral intake. However due 
TABLE 2: Summary of findings table: early oral feeding compared to delayed oral feeding for postoperative rehabilitation of total laryngectomy patients.

Early oral feeding compared to delayed oral feeding for postoperative rehabilitation of total laryngectomy patients

Patient or population: postoperative total laryngectomy patients

Settings: hospital

Intervention: early oral feeding

Comparison: delayed oral feeding

\begin{tabular}{|c|c|c|c|c|c|}
\hline \multirow{3}{*}{ Outcomes } & \multicolumn{2}{|c|}{ Illustrative comparative risks* $(95 \% \mathrm{CI})$} & \multirow{3}{*}{$\begin{array}{l}\text { Relative effect } \\
(95 \% \text { CI })\end{array}$} & \multirow{3}{*}{$\begin{array}{l}\text { Number of } \\
\text { participants } \\
\text { (studies) }\end{array}$} & \multirow{3}{*}{$\begin{array}{l}\text { Quality of the } \\
\text { evidence } \\
\text { (grade) }\end{array}$} \\
\hline & & Corresponding risk & & & \\
\hline & Delayed oral feeding & Early oral feeding & & & \\
\hline $\begin{array}{l}\text { Mortality at } 6 \text { months } \\
\text { Death rate } \\
\text { Follow-up: mean } 6 \text { months }\end{array}$ & 12 per 1000 & $\begin{array}{l}4 \text { per } 1000 \\
(1 \text { to } 26)\end{array}$ & $\begin{array}{l}\text { OR } 0.26 \\
(0.02 \text { to } 2.76)\end{array}$ & $\begin{array}{l}393 \\
\text { (7 studies) }\end{array}$ & $\begin{array}{l}\oplus \oplus \Theta \Theta \\
\text { low }^{1}\end{array}$ \\
\hline $\begin{array}{l}\text { Proportion of patients } \\
\text { developing pharyngocutaneous } \\
\text { fistula } \\
\text { Clinical diagnosis of fistula } \\
\text { Follow-up: median } 6 \text { months }\end{array}$ & 99 per 1000 & $\begin{array}{l}\mathbf{8 1} \text { per } \mathbf{1 0 0 0} \\
(43 \text { to } 148)\end{array}$ & $\begin{array}{l}\text { RR } \mathbf{0 . 8 2} \\
(0.44 \text { to } 1.50)\end{array}$ & $\begin{array}{l}393 \\
\text { (7 studies) }\end{array}$ & $\begin{array}{l}\oplus \oplus \Theta \Theta \\
\text { low }^{1}\end{array}$ \\
\hline $\begin{array}{l}\text { Pooled complications } \\
\text { Clavien-Dindo grading } \\
\text { Follow-up: median } 6 \text { months }\end{array}$ & 286 per 1000 & $\begin{array}{l}\mathbf{2 6 0} \text { per } \mathbf{1 0 0 0} \\
(166 \text { to } 409)\end{array}$ & $\begin{array}{l}\text { RR } 0.91 \\
(0.58 \text { to } 1.43)\end{array}$ & $\begin{array}{l}174 \\
\text { (4 studies) }\end{array}$ & $\begin{array}{l}\oplus \oplus \Theta \Theta \\
\text { low }^{1}\end{array}$ \\
\hline $\begin{array}{l}\text { Postoperative hospital stay } \\
\text { Days to discharge } \\
\text { Follow-up: median } 6 \text { months }\end{array}$ & $\begin{array}{l}\text { The mean postoperative } \\
\text { hospital stay in the } \\
\text { control groups was } \\
\mathbf{1 4 . 3 4} \text { days }\end{array}$ & $\begin{array}{l}\text { The mean postoperative } \\
\text { hospital stay in the } \\
\text { intervention groups was } \\
\mathbf{2 . 7 2} \text { lower } \\
\text { (5.34 to } 0.09 \text { lower) }\end{array}$ & & $\begin{array}{l}149 \\
\text { (3 studies) }\end{array}$ & $\begin{array}{l}\oplus \oplus \Theta \ominus \\
\text { low }^{1}\end{array}$ \\
\hline
\end{tabular}

${ }^{*}$ The basis for the control risk (e.g., the median control group risk across studies) is provided in footnotes. The corresponding risk (and its $95 \%$ confidence interval) is based on the assumed risk in the comparison group and the relative effect of the intervention (and its $95 \% \mathrm{CI}$ ).

CI: confidence interval; RR: risk ratio.

Grade working group grades of evidence.

High quality: further research is very unlikely to change our confidence in the estimate of effect.

Moderate quality: further research is likely to have an important impact on our confidence in the estimate of effect and may change the estimate.

Low quality: further research is very likely to have an important impact on our confidence in the estimate of effect and is likely to change the estimate.

Very low quality: we are very uncertain about the estimate.

${ }^{1}$ High risk in all studies.

${ }^{2}$ Control group risk calculated from included control groups in studies.

to the adoption of a multimodal approach to postoperative management that includes increased patient information, reduced surgical stress, effective antiemesis, anti-ileus therapy, dynamic pain relief, enforced oral nutrition, and early mobilization, hospital stays have been reduced and return to normal daily activities achieved quicker without increased rates of complications [37]. A biological plausibility for early feeding in total laryngectomy may result in shorter hospital admissions.

The factors which could explain why early oral feeding after laryngectomy is safe and potentially advantageous followed from the first observation that most fistulas in retrospective series in which a delayed feeding regime had been followed occurred before oral feeding had started [14]. Oral feeding is thought to have a positive effect on the gut mucosal barrier, reduce septic complications, and prevent a negative nitrogen balance that may improve gut immunity [14]. Up to $1.5 \mathrm{~L}$ of saliva is produced in a 24-hour period in health [40], which is safely swallowed past the anastomosis in most cases without fistula formation. Oral hygiene and the virulence of oral bacteria have been implicated in anastomotic leaks [41] and early feeding may prevent this. Early oral feeding may reduce the need for nasogastric feeding. The presence of a nasogastric tube has been thought to be a factor in promoting fistulas [42] and an important consideration in delayed feeding groups as they are likely to have a nasogastric tube until oral feeding is achieved.

A nasogastric tube has been suggested to be a risk factor for gastroesophageal reflux [43]. Gastric organisms may affect wound healing. In a study of patients in intensive care fed with a nasogastric tube and on antireflux medication simultaneous culture of gastric gram-negative bacteria was isolated from the upper airways and the stomach [44]. De Jong and Struben reported a reduction in fistula rates from $48 \%$ to $29 \%$ with the reduced use of nasogastric feeding [13]. Reduction in the use of nasogastric tubes may offer other positive benefits. Pressure on the sutures line and irritation of the healing wound have been postulated as possible negative factors in which 
a nasogastric tube may affect fistula rates [8, 45]. Patients often find them uncomfortable and reinsertion following accidental displacement is not an uncommon scenario. This may injure the healing neopharynx and lead to physical and medical restraints [46].

Overall psychological benefits of quicker oral and speech rehabilitation are likely to be greater in early oral feeding patients. Prasad et al. reported in their control group a desire for nasogastric tube removal and initiation of oral feeds [14]. It has also been reported that patients feel more comfortable and confident without a feeding tube [45]. A quicker discharge from hospital and reduction in hospital stay may also be positive effects of early oral feeding [31, 32].

Weakness of Review. The quality of evidence is summarized in the risk of bias summary in Figure 2. In the detection of harmful events RCTs and case controlled studies were included. Three of the four RCT studies identified were at a high risk of bias because the methods used for randomizations were not described. The inclusion of patients seems to suffer from strict inclusion criteria that may affect the applicability of evidence to all patients. Two case controlled studies included a control group that was a contemporaneous group of consecutive patients [32]. The other, however, used historic data [31]. Once the data had been combined and analysed, there was imprecision in the effect estimates as a number of outcomes had wide confidence intervals. Therefore further higher quality studies may change the effect estimates produced in this review of early oral feeding following total laryngectomy.

\section{Conclusion}

Early oral feeding appears to have a similar incidence of complications and has the potential to shorten the length of hospital stay. Further well-designed RCTs are necessary because of weaknesses in the included evidence.

\section{Disclosure}

There are no external interests. This review has been produced as part of an M.S. degree. There has been no additional help outside authorship used in this review and all information sources have been referenced. Endnote X6.0.2 was used to reference this document. There are no specific financial interests, relationship, and affiliations relevant to the subject of the paper.

\section{Conflict of Interests}

There are no financial or personal relationships with other people or organizations that could inappropriately influence (bias) the authors' actions.

\section{Authors' Contribution}

Ashley Hay contributed to conception of idea, writing of protocol, searching of results, data extraction, analysis, and writing of final review. Kurinchi Gurusamy supported construction of protocol and designed and performed literature search and review of final paper. Lisa Pitkin made simultaneous selection of studies from search and acted as a second data extractor.

\section{References}

[1] H. F. Robinson, "International practice of laryngectomy rehabilitation," Current Opinion in Otolaryngology and Head and Neck Surgery, vol. 21, no. 3, article 185, 2013.

[2] A. A. Forastiere, H. Goepfert, M. Maor et al., "Concurrent chemotherapy and radiotherapy for organ preservation in advanced laryngeal cancer," The New England Journal of Medicine, vol. 349, pp. 2091-2098, 2003.

[3] The Department of Veterans Affairs Laryngeal Cancer Study Group, "Induction chemotherapy plus radiation compared with surgery plus radiation in patients with advanced laryngeal cancer," The New England Journal of Medicine, vol. 324, no. 24, pp. 1685-1690, 1991.

[4] Health \& Social Care Information Centre, "Hospital Episode Statistics, Admitted Patient Care-England, 2011-12," 2012, http://www.hscic.gov.uk/hes.

[5] P. T. Maddox and L. Davies, "Trends in total laryngectomy in the era of organ preservation: a population-based study," Otolaryngology: Head and Neck Surgery, vol. 147, no. 1, pp. 8590, 2012.

[6] W. B. Armstrong, D. E. Vokes, and R. H. Maisel, "Malignant tumours of the larynx," in Cummings Otolaryngology Head \& Neck Surgery, P. W. Flint and C. W. Cummings, Eds., Mosby/Elsevier, Philadelphia, Pa, USA, 2010.

[7] N. Agrawal and D. Goldenberg, "Primary and Salvage Total Laryngectomy," Otolaryngologic Clinics of North America, vol. 41, no. 4, pp. 771-780, 2008.

[8] S. E. Boyce and A. D. Meyers, "Oral feeding after total laryngectomy," Head and Neck, vol. 11, no. 3, pp. 269-273, 1989.

[9] C. H. Rassekh and B. H. Haughey, "Total laryngectomy and laryngopharyngectomy," in Cummings Otolaryngology Head \& Neck Surgery, W. C. C. W. Flint Paul, Ed., Mosby/Elsevier, Philadelphia, Pa, USA, 2010.

[10] E. L. Applebaum and H. L. Levine, "Pharyngeal reconstruction after laryngectomy," Laryngoscope, vol. 87, no. 11, pp. 1884-1890, 1977.

[11] R. W. Cantrell, "'How I do it'-head and neck. A targeted problem and its solution. Pharyngeal fistula: prevention and treatment," Laryngoscope, vol. 88, no. 7, pp. 1204-1208, 1978.

[12] T. D. Briant, "Spontaneous pharyngeal fistula and wound infection following laryngectomy.," Laryngoscope, vol. 85, no. 5, pp. 829-834, 1975.

[13] P. C. De Jong and W. H. Struben, "Pharyngeal fistulae after laryngectomy," Journal of Laryngology and Otology, vol. 84, no. 9, pp. 897-903, 1970.

[14] K. C. Prasad, S. Sreedharan, N. K. Dannana, S. C. Prasad, and S. Chandra, "Early oral feeds in laryngectomized patients," Annals of Otology, Rhinology and Laryngology, vol. 115, no. 6, pp. 433438, 2006.

[15] J. P. T. Higgins and S. Green, Cochrane Handbook for Systematic Reviews of Interventions Version 5.1.0, The Cochrane Collaboration, 2011. 
[16] P. A. Clavien, J. Barkun, M. L. De Oliveira et al., "The claviendindo classification of surgical complications: five-year experience," Annals of Surgery, vol. 250, no. 2, pp. 187-196, 2009.

[17] L. L. Kjaergard, J. Villumsen, and C. Gluud, "Reported methodologic quality and discrepancies between large and small randomized trials in meta-analyses," Annals of Internal Medicine, vol. 135, no. 11, pp. 982-989, 2001.

[18] D. Moher, B. Pham, A. Jones et al., "Does quality of reports of randomised trials affect estimates of intervention efficacy reported in meta-analyses?" The Lancet, vol. 352, no. 9128, pp. 609-613, 1998.

[19] K. F. Schulz, L. Chalmers, R. J. Hayes, and D. G. Altman, "Empirical evidence of bias: dimensions of methodological quality associated with estimates of treatment effects in controlled trials," Journal of the American Medical Association, vol. 273, no. 5, pp. 408-412, 1995.

[20] L. Wood, M. Egger, L. L. Gluud et al., "Empirical evidence of bias in treatment effect estimates in controlled trials with different interventions and outcomes: meta-epidemiological study," $B M J$, vol. 336, no. 7644, pp. 601-605, 2008.

[21] The Nordic Cochrane Centre, The Cochrane Collaboration, Copenhagen.

[22] R. DerSimonian and N. Laird, "Meta-analysis in clinical trials," Controlled Clinical Trials, vol. 7, no. 3, pp. 177-188, 1986.

[23] D. L. Demets, "Methods for combining randomized clinical trials: Strengths and limitations," Statistics in Medicine, vol. 6, no. 3, pp. 341-348, 1987.

[24] D. J. Newell, "Intention-to-treat analysis: implications for quantitative and qualitative research," International Journal of Epidemiology, vol. 21, no. 5, pp. 837-841, 1992.

[25] M. Egger, G. D. Smith, M. Schneider, and C. Minder, "Bias in meta-analysis detected by a simple, graphical test," The British Medical Journal, vol. 315, no. 7109, pp. 629-634, 1997.

[26] P. Macaskill, S. D. Walter, and L. Irwig, "A comparison of methods to detect publication bias in meta-analysis," Statistics in Medicine, vol. 20, no. 4, pp. 641-654, 2001.

[27] H. Seven, A. B. Calis, and S. Turgut, "A randomized controlled trial of early oral feeding in laryngectomized patients," Laryngoscope, vol. 113, no. 6, pp. 1076-1079, 2003.

[28] H. A. Sharifian, M. Najafi, and M. Khajavi, "Early oral feeding following total laryngectomy," Tanaffos, vol. 7, no. 2, pp. 64-70, 2008.

[29] J. Song, S. Jing, and H. Shi, "The clinical observation of early oral feeding following total laryngectomy," Journal of Clinical Otorhinolaryngology, vol. 17, no. 9, pp. 527-528, 2003 (Chinese).

[30] P. Volling, H. Singelmann, and O. Ebeling, "Incidence of salivary fistulas subject to the timing of oral feeding after laryngectomy," HNO, vol. 49, no. 4, pp. 276-282, 2001.

[31] J. Aswani, M. Thandar, J. Otiti, and J. Fagan, "Early oral feeding following total laryngectomy," Journal of Laryngology and Otology, vol. 123, no. 3, pp. 333-338, 2009.

[32] J. E. Medina and A. Khafif, "Early oral feeding following total laryngectomy," Laryngoscope, vol. 111, no. 3, pp. 368-372, 2001.

[33] M. Alonso Justo, Cáncer Laríngeo, Paz Montalvo, Madrid, Spain, 1954.

[34] F. Aprigliano, "Use of the nasogastric tube after total laryngectomy: is it truly necessary?" Annals of Otology, Rhinology and Laryngology, vol. 99, no. 7, pp. 513-514, 1990.

[35] A. L. Cavalot, C. F. Gervasio, G. Nazionale et al., "Pharyngocutaneous fistula as a complication of total laryngectomy: review of the literature and analysis of case records," OtolaryngologyHead and Neck Surgery, vol. 123, no. 5, pp. 587-592, 2000.

[36] M. U. Akyol, C. Ozdem, and S. Celikkanat, "Early oral feeding after total laryngectomy," Ear, Nose and Throat Journal, vol. 74, no. 1, pp. 28-30, 1995.

[37] T. Bisgaard and H. Kehlet, "Early oral feeding after elective abdominal surgery-what are the issues?" Nutrition, vol. 18, no. 11-12, pp. 944-948, 2002.

[38] H. Hur, S. G. Kim, J. H. Shim et al., "Effect of early oral feeding after gastric cancer surgery: a result of randomized clinical trial," Surgery, vol. 149, no. 4, pp. 561-568, 2011.

[39] A. El Nakeeb, A. Fikry, T. El Metwally et al., "Early oral feeding in patients undergoing elective colonic anastomosis," International Journal of Surgery, vol. 7, no. 3, pp. 206-209, 2009.

[40] B. Bailey, J. Johnson, and S. Newlands, Head and Neck SurgeryOtolaryngology, Lippincott Williams \& Wilkins, Philadelphia, $\mathrm{Pa}$, USA, 2006.

[41] R. W. Postlethwait, "Complications of the anastomosis: leak and stricture," in International Trends in General Thoracic Surgery, pp. 288-295, Saunders, Philadelphia, Pa, USA, 1988.

[42] O. Kleinsasser, Tumors Of The Larynx And Hypopharynx, Thieme Publishing Group, Stuttgart, Germany, 1988.

[43] J. Ibanez, A. Penafiel, J. M. Raurich, P. Marse, R. Jorda, and F. Mata, "Gastroesophageal reflux in intubated patients receiving enteral nutrition: effect of supine and semirecumbent positions," Journal of Parenteral and Enteral Nutrition, vol. 16, no. 5, pp. 419-422, 1992.

[44] G. C. Du Moulin, D. G. Paterson, J. Hedley-Whyte, and A. Lisbon, "Aspiration of gastric bacteria in antacid-treated patients: a frequent cause of postoperative colonisation of the airway," The Lancet, vol. 1, no. 8266, pp. 242-245, 1982.

[45] L. Soylu, M. Kiroglu, B. Aydogan et al., "Pharyngocutaneous fistula following laryngectomy," Head \& Neck, vol. 20, pp. 2225, 1998.

[46] K. K. Helm and R. Chernoff, Geriatric Nutrition, Aspen, South Holland, Netherlands, 1995. 


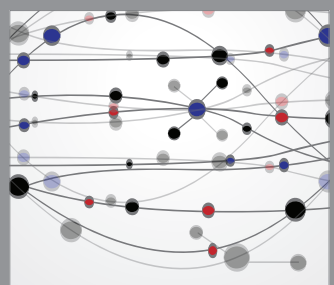

The Scientific World Journal
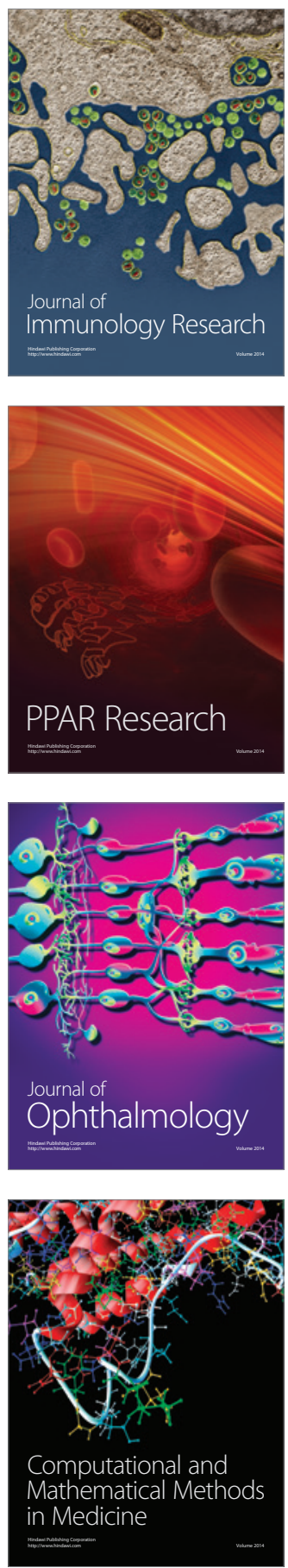

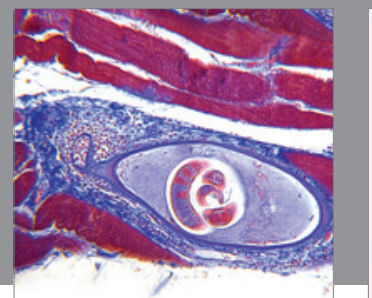

Gastroenterology

Research and Practice
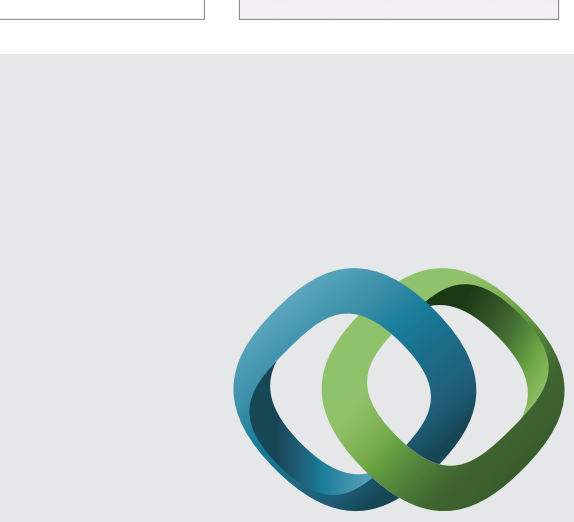

\section{Hindawi}

Submit your manuscripts at

http://www.hindawi.com
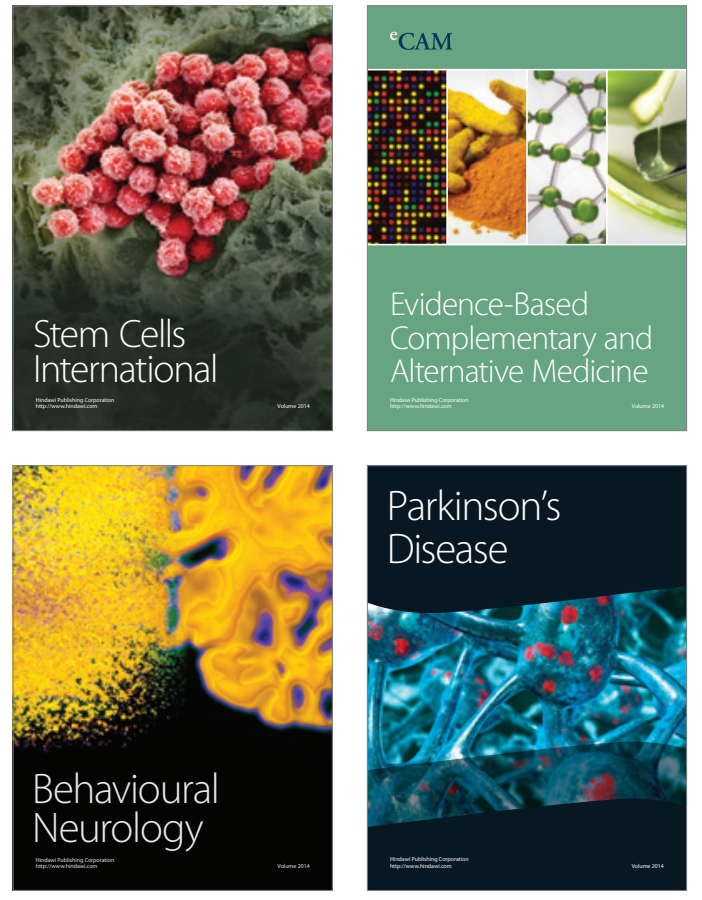
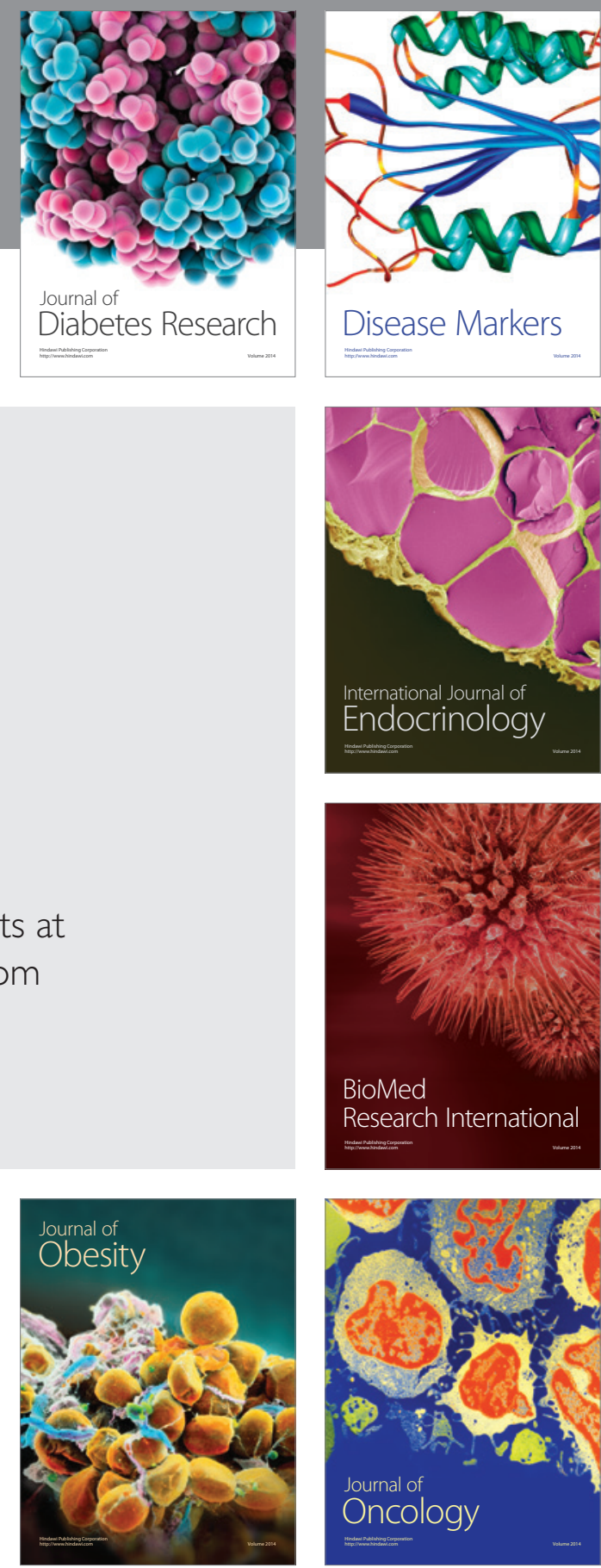

Disease Markers
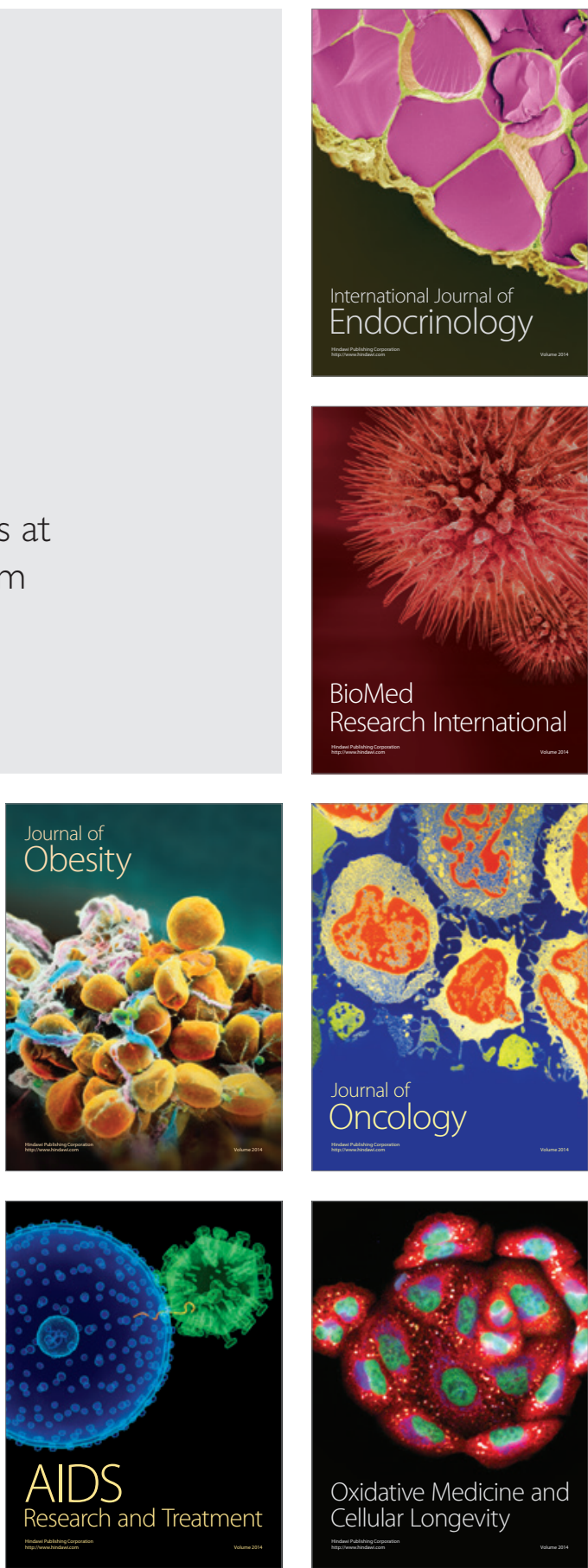